\title{
COOPERATION AND COMPETITION IN MANUFACTURER-KEY RETAILER RELATIONSHIPS: A BUSINESS MODEL PERSPECTIVE
}

\section{Marzanna Katarzyna Witek-Hajduk', Piotr Zaborek ${ }^{2}$}

\footnotetext{
1 Warsaw School of Economics, Institute of International Management and Marketing, Poland, ORCID: 0000-00033670-3587, mwitek@sgh.waw.pl;

2 Warsaw School of Economics, Institute of International Management and Marketing, Poland, ORCID: 0000-00018809-5371, piotr.zaborek@sgh.waw.pl.
}

\begin{abstract}
The study investigates relationships between manufacturers and their key retailers in the Polish durable consumer goods industry from the manufacturer's perspective. The importance of this topic has been growing with such global phenomena in retailing as concentration and internationalization, the emergence of mega-retailers, the growth of private brands and the rise of the Internet. The balance of this factors has led to a shift in bargaining power towards retailers. On this backdrop, the goal of this study is to examine how a manufacturer's dependence on the key retailer shapes this relationship in terms of its cooperative/competitive dimensions, scope and outcomes, and if the dominant business models of manufacturers are moderating the focal relationship. The three types of business models include: Traditionalists (unwilling to enter into longterm partnerships despite lacking unique assets), Market Players (the most flexible of the three in choosing their partners and deciding on the scope of cooperation due to their unique assets) and Contractors (the most dependent on their business partners due to their lack of well-developed marketing functions). Data for the study were collected through a representative CATI survey of 580 manufacturers and analyzed with PLS structural equation modeling. The findings indicate that high manufacturer dependence on the key retailer can have positive impacts on manufacturers by inducing greater benefits from cooperation. This effect is the most pronounced among Traditionalists and is the least visible in Market Players, with Contractors showing intermediate effects. Some likely reasons for these positive effects include know-how transfers, extension of the distribution network, manufacturing contracts for private labels and marketing support from the key retailer.
\end{abstract}

Keywords: Manufacturer-retailer cooperation and coopetition, manufacturer-retailer relationships, business models, durable consumer goods, Poland.

JEL Classification: D22, M10, M21.

APA Style Citation: Witek-Hajduk, M. K., \& Zaborek, P. (2020). Cooperation and Competition in Manufacturer-Key Retailer Relationships: A Business Model Perspective. E\&M Economics and Management, 23(1), 167-183. https://doi.org/10.15240/tul/001/2020-1-012

\section{Introduction}

Relationships in the supply chain have been a longstanding theme of research (e.g. Ailawadi et al., 2010; Corsten \& Kumar, 2005; Vlachos et al., 2008). Manufacturer-retailer relationships have changed in recent decades due to the growing power of retailers (Amato \& Amato, 2009) reinforced by concentration processes in retailing (Burt \& Sparks, 2003), the emergence of mega-retailers and their internationalization, and the rise of the Internet. The shift in bargaining power toward retailers is manifested by the growing market shares of private brands (Chimhundu, 2011). On the heels of these trends, changes have come in business models of both retailers and producers (e.g. Ritala et al., 2014; 
Witek-Hajduk, 2017). The role of retailers has evolved "from mere service providers to market makers" (Hamilton \& Petrovic, 2011). The growing power of retailers has prompted many manufacturers of consumer goods to establish their own or controlled retail channels and/or to produce goods under retailers' private labels often competing with their own brands. Consequently, various forms of cooperation and competition have developed giving rise to the phenomenon of coopetition (Kim et al., 2013).

Many scholars contributed conceptual papers on inter-organizational cooperation and coopetition (e.g. Gnyawali \& Park, 2016), but much fewer offered empirical evidence, especially from the manufacturer's perspective. What little empirical research is available is mostly qualitative (Chow et al., 2011) with only a few studies relying on quantitative data (e.g. Teller et al., 2016), often taking the retailer's viewpoint and centering on fast moving consumer goods (Kim et al., 2013). The current study provides quantitative evidence on cooperation and coopetition between the manufacturer and its key retailing partner. Its unique aspect is that it looks at these interactions through the lens of the manufacturer's business model, following suggestions in the literature that the dominant business model can affect cooperative/coopetitive behavior and its outcomes (e.g. Storbacka, 2011).

This research proposes and tests a structural equation model on a random sample of 580 Polish manufacturers of consumer goods to investigate how the manufacturers' dependence on their key retailing partner shapes the nature and outcomes of cooperative/coopetitive relationships. We compare three manufacturing business models while accounting for company size (medium and large employment) and ownership (solely Polish or at least partially controlled by foreign capital).

The paper is organized as follows. First, we overview pertinent literature sources and develop hypotheses. Next, we outline the conceptual framework and research methods. And finally, we present findings, discuss conclusions and offer recommendations.

\section{Literature Review and Research Hypotheses}

Inter-firm relationships are considered from the perspective of both cooperation and competition - the concepts that are no longer treated as incompatible exchange approaches but parts of the same relationship. Bengtsson, Hinttu and Kock (2003) distinguish between four types of relations: cooperation (without competition), competition (without cooperation), coexistence (no competition or cooperation), and coopetition (a combination of cooperative and competitive behaviors of market rivals who benefit by complementing each other in some activities but competing in other parts of the value chain).

Manufacturer-retailer relationships often comprise a mixture of horizontal and vertical cooperation and competition (e.g. Kotzab \& Teller, 2003; Teller et al., 2016) with varying intensity of cooperation and competition streams. These relationships can be of two types: "pure", traditional cooperation (a lack of competition between a manufacturer and retailer) or coopetition (a mix of both competition and cooperation between the parties). Coopetition frequently occurs when a manufacturer maintains its own retail stores competing with a retailer's facilities and/or a retailer sells its private labels that compete with the manufacturer brands (Kim et al., 2013). The cooperative dimension of this relationship involves joint actions of the manufacturer and retailer to pursue joint benefits, while the competitive dimension is reflected in individual actions aimed at achieving private goals by outperforming the partner (Kim et al., 2013).

Among key issues in inter-organizational relationship studies are power and dependence (e.g. Essabbara, Zrikem, \& Zolghadri, 2016). Dapiran and Hogarth-Scott (2003) identify two sources of power in the manufacturer-retailer relationship: traditional mediated power (based on rewards derived from the ability to influence the allocation of incentives, and coercive, linked to threats, punishments and sanctions) and non-mediated power (expert knowledge and privileged information in a particular area). Dependence implies that one of the parties of a manufacturer-retailer relationship has more power over the other party (Tangpong et al., 2015). This power means that the goals of the weaker party, which can be achieved in this relationship, are mediated by the stronger partner (Matopoulos et al., 2007). A manufacturer's power over its key retailer results from the retailer's dependence on the producer and vice versa. Because of the reciprocal character of the manufacturer-retailer 
relationship, the interdependency between the parties is closely tied to the balance of power between them. Tellefsen and Thomas (2005) state that the dependence in the inter-firm relationship exists either when benefits from that relation are crucial to the weaker company or when there are few possibilities of replacing the stronger partner. Manufacturer-retailer power asymmetry increases dependence in favor of the more powerful company and exacerbates the imbalance in risk-reward sharing, inhibiting the intensity of cooperation (Matopoulos et al., 2007). The side of a relationship that wields more power can use it to impose its requirements on the weaker party and it can aggravate conflicts strengthening the competitive dimension of the relationship (Radaev, 2013).

The literature sources discussed thus far indicate that increased dependence resulting from asymmetry of power fosters the competitive aspect of the relationship and inhibits its cooperative dimension. Therefore, we hypothesize that:

H1: The manufacturer's dependence on the key retailer is positively associated with the competitive dimension of the manufacturerretailer relationship.

H2: The manufacturer's dependence on the key retailer is negatively associated with the cooperative dimension of the manufacturerretailer relationship.

Manufacturers can cooperate with retailers in a wide range of value chain processes (e.g. Swoboda et al., 2010; Park, 2004; Ailawadi et al., 2010), including innovations (R\&D, market analyses, trend recognition, product/ assortment design, launching new products/ brands), logistics (manufacturing, distribution, stock management, sales floor management) and customer-centric functions (category management, promotional activities, shop design, price promotions, loyalty programs, customer services). Manufacturer-key retailer relationships vary in scope with interactions extending across different value chain processes. According to Bengtsson and Kock (2000), firms tend to cooperate more in the value chain activities that are further away from customers and compete in the activities that are closer to customers. Overall, the literature is clear that cooperation tends to result in more joint activities and an increased cooperation scope, while competition makes parties more reticent to engage in joint activities and add shared resources to the relationship. Thus, we hypothesize:

H3: Cooperation scope is negatively associated with the competitive dimension of the manufacturer-retailer relationship ( $\mathrm{H} 3 \mathrm{a}$ ), but positively associated with its cooperative dimension $(H 3 b)$ and the manufacturer's dependence on the key retailer $(\mathrm{H} 3 \mathrm{c})$.

Strategies of cooperation and coopetition are implemented to improve the performance of cooperating firms (Geraudel \& Salvetat, 2014; Pereira, Brito, \& Mariotto, 2013). They allow partners in a manufacturer-retailer relationship to focus on their core competences and main processes in the value chain, which helps to achieve economies of scale and acquire new skills and capabilities (Park et al., 2004). Consequently, a company can avoid internalizing activities that are not congruent with its assets and competencies by using strategic resources obtained from the partner and by establishing access barriers to these resources for third parties, which helps create a semi-permanent competitive advantage (Medcof, 2001). Joint competitive advantage, derived from the relational rent generated by the unique assets that cannot be obtained individually (Lavie, 2006) is a key benefit of the cooperative dimension of the manufacturerretailer relationship. Researchers (e.g. Qubina et al., 2006; Kumar \& Steenkamp, 2007; Gomez-Arias et al., 2008) identified multiple benefits for manufacturers from cooperation with retailers, including: economies of scale, better capacity utilization, increased profitability, reduced production costs, access to proprietary distribution channels and marketing skills, lowered expenditures on the creation of manufacturer brands, support for new product development, improved inventory management, increased manufacturer brand awareness, higher resistance to economic crises, increased market share, improvement of customer preferences, and diversification of product lines. The magnitude of benefits is, therefore, a function of the scope of cooperation and the range of joint activities. Manufacturers and retailers cooperate in value chains to achieve joint benefits for both parties while simultaneously competing for individual benefits (Kim et al., 2013). Many scholars (e.g. Palmatier et al., 2006) assert that 
cooperation in the supply chain leads to better results than rivalry. Kim et al. (2013) discuss the impact of cooperative, competitive and synergistic (coopetitive) strategies in retailersupplier relations on joint and individual benefits. Accordingly, the stronger is the cooperative dimension of the coopetition strategy of the retailer, the greater are the joint benefits shared with the focal supplier, but supply flexibility seems to be unaffected. On the other hand, a stronger competitive dimension in a retailer's strategy does not correspond with greater joint benefits, but it tends to increase supply flexibility. Of the three strategies, the synergistic one is the most balanced option on account of its positive effect on both joint benefits and supply flexibility. The authors conclude that competing with the focal supplier does not help the retailer achieve greater joint benefits (Kim et al., 2013). According to Qubina et al. (2006), benefits for manufacturers from cooperation with retailers in producing private labels depend on their relative competitive positions, in particular if a manufacturer is the market leader. Soberman and Parker (2006) observe that when a retailer and a manufacturer have significant market power, both sides of the relationship may benefit from offering the retailer's brands of the equivalent quality to the manufacturer's brands. It is also noted that a manufacturer's cooperation with only one retailer can make it difficult to achieve such benefits as economies of scale and cost reductions (Corsten \& Felde, 2005). Producing private brands carries several non-trivial risks for the manufacturer, as it can compromise its brands' equity, including image, raise complexity of operational processes thus inflating costs, and increase dependence on the retailer in no small part due to sharing knowledge on the market and proprietary innovative technologies (e.g. Rubio \& Yagüe, 2008; Kumar \& Steenkamp, 2007). These negative effects are the more likely to occur the higher is the manufacturer's dependence on the key retailer.

From the above discussion of cooperation benefits and their antecedents, we propose:

H4: Relationship benefits are positively associated with the cooperation scope (H4a), the cooperative dimension of the relationship (H4b), and negatively associated with the manufacturer's dependence on the key retailer $(\mathrm{H} 4 \mathrm{C})$ and the competitive dimension of the relationship (H4d).
Some authors suggested investigating relationships in the supply chain through the lens of business models used by relationship participants, believing that this perspective helps to identify new data patterns and better explains existing relations (e.g. Trkman et al., 2015). From an analytical viewpoint, the concept of a business model is considered an effective, holistic approach to systemic examination of companies, particularly their value propositions, resource allocation and performance (Zott et al., 2011). The literature offers many different views on the business model: e.g. as the business logic of a company in a particular business unit (Osterwalder et al., 2005), or the way an organization, together with its key stakeholders, creates value propositions for customers (Kallio et al., 2006). There is, however, no consensus among scholars on what constitutes a business model. According to Osterwalder et al. (2005), a business model consists of a value proposition, customer segments, customer relationships, key activities, key partners, key resources, cost structure, channels and revenue streams. Dudzik et al. (2008) state that a business model comprises a value proposition for customers, processes in the internal value chain, company relationships with other firms in the supply chain that serve to create, offer and deliver customer value, and revenue streams. Despite all these differences, a recurring theme in various perspectives on business models is that this concept is not limited to the domain under the exclusive control of a company, but it also involves other actors, such as suppliers and distributors and is closely linked with an organization's architecture (Osterwalder et al., 2005). These characteristics make the business model a relevant theoretical framework to employ in the context of manufacturerretailer relationships, where different roles are assigned to involved parties and different resource configurations are used. According to the resource-based view, the dynamics and outcomes of business-to-business cooperation are dependent on how resources and processes within internal value chains were configured and what was outsourced to external partners in the value chain. In fact, one of the premises for cooperation in the value chain is the ability for sharing complementary resources. As Benson-Rea et al. (2013) put it, "business models complement each other the more they share major physical assets, capabilities and 
resources". Moreover, sometimes the decision to cooperate entails improving or replacing the business model or developing a new one (Storbacka, 2011).

To identify the dominant business models of manufacturers, we used a classification by Dudzik and Witek-Hajduk (2007) distinguishing five categories of business models: Traditionalists, Market Players, Contractors, Distributors and Integrators. Two of the business models are reserved for retailers (Distributor and Integrator), but the following three categories can be employed by manufacturers (Witek-Hajduk, 2017):

1. Traditionalist - relies on offering conventional functional benefits from its products at a competitive price; it does not possess unique resources (a strong brand, patents, technology); its internal value chain is long, including R\&D, production, marketing, sales and after-sales services; most of the revenues are from the sales of manufactured products.

2. Market player - derives its value proposition for customers from strong brands and unique working relationships with other members of the value chain; it has unique resources (advanced technology, strong brands, patents, unique designs, recipes and superior managerial skills); its internal value chain is long, including R\&D, production, marketing, sales and aftersales services; it tends to be the leader of its supply chain; its returns are sourced from selling goods under own brands, supplemented by proceeds from licensing and franchising fees.

3. Contractor - specializes in subcontractor manufacturing, often using a partner's designs; its value proposition is cost efficiency combined with functional product benefits; its supply chain is short and focused on manufacturing processes; the bulk of the revenues comes from manufacturing contracts.

These three business models entail different approaches to cooperation and competition within supply chains, which was the main reason for choosing this classification as part of the conceptual framework in this study. Traditionalists tend to be unwilling to enter into long-term partnerships and are reluctant outsourcers, even though they rarely possess unique assets to merit keeping all functions internal. Market Players are the most flexible of the three in choosing their partners and deciding on the scope of cooperation. Their unique assets make it possible to easily scale up and down the number of services performed jointly with a partner. In this typology, Contractors are liable to be the most dependent on business partners due to their lack of welldeveloped marketing functions. Accordingly, they need to rely on retailers to contract with them manufacturing orders for private labels.

Considering the current state of knowledge on the role of business models in shaping manufacturer-retailer relationships it is difficult to develop precise directional hypotheses, however the literature offers strong reasons to believe that manufacturers following different business models will show differences across the whole conceptual framework of the study. Thus, we posit:

H5: Manufacturers following different business models will have different values of regression weights for associations indicated in hypotheses $\mathrm{H} 1$ through $\mathrm{H} 4$.

\section{Conceptual Framework and Research Methods}

In this study we model vertical relationships in the supply chain between manufacturers and retailers with a framework that involves five composite variables (or constructs): 1) the manufacturer's dependence on the key retailer; two dimensions of manufacturerretailer relationships: 2) cooperation and 3) competition; 4) cooperation scope; and 5) cooperation benefits from the manufacturer's perspective. The links among studied variables and pertinent hypotheses are illustrated in Fig. 1.

The model assumes that the main driver of a manufacturer-key retailer relationship is the manufacturer's dependence on the key retailer, which determines the relative bargaining power of both parties. The manufacturer's dependence on the key retailer is shaping the form of the relationship through the strength of its cooperative and competitive dimensions. Competitive and cooperative attitudes and behaviors drive the scope of the cooperation by determining the number of jointly performed tasks and functions. The final dependent variable in the model is cooperation benefits, which is hypothesized to be a consequence of the scope of cooperation with possibly weaker 


\section{Fig. 1: Conceptual model and hypotheses of the study}

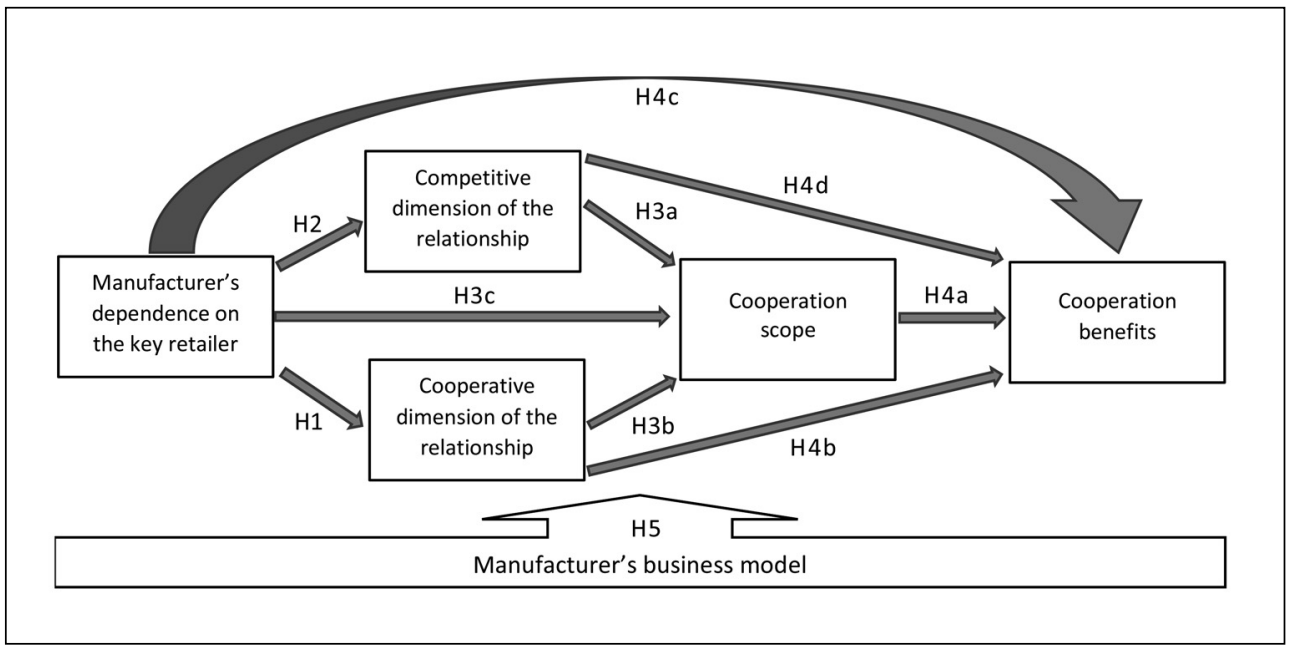

Source: own elaboration

direct influences from other variables in the framework.

Empirical data were collected through a CATI survey of 613 managers of medium and large manufacturers of consumer durable products operating in Poland at the end of 2015 and the beginning of 2016. Sample units were selected at random from a database encompassing all Polish firms meeting the eligibility criteria, thus ensuring sample representativeness. After removing records with incomplete and faulty answers, the net sample size was 580 .

Respondents were asked questions about their relationships with the key retailer who according to the adopted operationalization accounted for the largest percentage of sales of durable consumer goods produced by their firm over the year before the interview. They were also given characteristics of three business models from Dudzik and Witek-Hajduk (2007) and were requested to indicate the one best describing their own firm. Regarding identified dominant business models, the net sample comprised of 321 Traditionalists, 131 Contractors and 128 Market Players.

Following guidance in earlier research, the concepts of a manufacturer's dependence on the key retailer, as well as cooperative and competitive dimensions of the relationship were assumed to be reflective latent variables and operationalized with sets of Likert-scale statements (Kim et al., 2013; Witek-Hajduk \& Zaborek, 2016). In reflective constructs, the direction of relationship goes from a latent variable to its indicators, as the latent variable is assumed to be the cause and indicators reflect some of its effect. In such a reflective setup, indicators are expected to be highly correlated. On the other hand, the scope and benefits of cooperation were considered formative constructs, where causality flows from indicators to the latent variables, and the indicators can represent independent causes that do not need to be correlated. Therefore, and what is a common practice, formative indicators of cooperation scope and benefits were operationalized through two lists of binary items with yes or no answers. Tab. 1 shows the items used in the questionnaire together with factor loadings and other metrics that are explained later in the paper.

With reflective constructs, a latent variable is typically estimated through linear transformations based on the amount of shared variance in indicators, while formative constructs are often represented by indices computed as the means of component indicators. These routines were also used in 
Indicators

Manufacturer's dependence on the key retailer

Traditionalists: $\mathrm{AVE}=0.568 ; \mathrm{MSV}=0.175 ;$ C's alpha $=0.814 ;$ Market Players: $\mathrm{AVE}=0.521$; MSV $=0.214 ;$ C's alpha $=0.764 ;$ Contractors: $A V E=0.714 ;$ MSV $=0.091 ;$ C's alpha $=0.809$

\begin{tabular}{|c|c|c|}
\hline \multicolumn{3}{|c|}{ Factor loadings } \\
\hline $\begin{array}{c}\text { Traditiona- } \\
\text { lists } \\
(n=321)\end{array}$ & $\begin{array}{c}\text { Market } \\
\text { Players } \\
(n=128)\end{array}$ & $\begin{array}{c}\text { Contractors } \\
(n=131)\end{array}$ \\
\hline
\end{tabular}

In the Polish market of durable consumer goods there are no other retailers to offer us similar terms and conditions as our key retailer.

The cost of changing our key retailer to a similar one would be too high.

It would be difficult to compensate for lost earnings from cooperating with our key retailer.

It would be difficult to compensate for lost revenues from cooperating with our key retailer.

It is not possible for us to offer our products through other retail networks.

\begin{tabular}{|c|c|c}
\hline 0.723 & 0.638 & 0.573 \\
\hline 0.766 & 0.837 & 0.883 \\
\hline 0.791 & 0.779 & 0.752 \\
\hline 0.795 & 0.761 & 0.934 \\
\hline 0.690 & 0.559 & 0.430 \\
\hline
\end{tabular}

\section{Cooperative dimension of relationship}

Traditionalists: $\mathrm{AVE}=0.680 ; \mathrm{MSV}=0.265 ; \mathrm{C}^{\prime}$ s alpha $=0.767 ;$ Market Players: $\mathrm{AVE}=0.720$;

MSV $=0.214 ;$ C's alpha $=0.799 ;$ Contractors: $\mathrm{AVE}=0.686 ; \mathrm{MSV}=0.249 ; \mathrm{C}$ 's alpha $=0.779$

\begin{tabular}{l|l|l|l}
\hline We carry out joint projects with the key retailer. & 0.832 & 0.936 & 0.896 \\
\hline We coordinate supply chain activities with the key retailer. & 0.864 & 0.892 & 0.890 \\
\hline $\begin{array}{l}\text { We have a contract agreement with the key retailer that } \\
\text { regulates our cooperation. }\end{array}$ & 0.776 & 0.698 & 0.681 \\
\hline
\end{tabular}

\section{Competitive dimension of relationship}

Traditionalists: $\mathrm{AVE}=0.523 ; \mathrm{MSV}=0.265 ; \mathrm{C}$ 's alpha $=0.667 ;$ Market Players: $\mathrm{AVE}=0.617$;

MSV $=0.040 ; C$ 's alpha $=0.734 ;$ Contractors: $A V E=0.528 ;$ MSV $=0.072 ;$ C's alpha $=0.650$

Our relationship with the key retailer is best described as "fighting for a fixed pie".

We often find ourselves in conflict with the key retailer over the terms and conditions of cooperation.

The key retailer forces on us their terms and conditions of cooperation.

\begin{tabular}{l|l|l|l} 
& 0.934 & 0.703 & 0.921 \\
\hline & 0.420 & 0.505 & 0.647 \\
\hline
\end{tabular}

\section{Cooperation scope}

Factor loadings and other metrics are not computed for formative constructs

Our cooperation with the key retailer includes: 1) launching new brands and products on the market; 2 ) product category management at the key retailer's stores; 3 ) manufacturing contracts from the key retailer involving exclusive or non-exclusive products; 4) supply management; (5) acquiring market information; 5) promotional activities; 6) customer service; 7) sales discounts; 8) loyalty programs.

\section{Cooperation benefits}

Factor loadings cannot be computed for a formative construct

The relationship with the key retailer enabled us to: 1) limit risk; 2) achieve and/or maintain cost advantage over other manufacturers; 3 ) increase productivity; 4) strengthen our relationships with consumers; 5) develop our bargaining power with suppliers; 6) improve the image of our brands/ company; 7) enhance the quality of our products and services; 8) increase the visibility of our products at the key retailer's points of sale; 9) increase our marketing know-how; 10) raise our market share; 11) gain access to new geographical markets, new segments of consumers and/or distribution channels. 
the current study. All required transformations and computations on raw data to explore regression paths among latent variables were performed with SMART PLS 3.2, a statistical software package for estimating structural equation models with the partial least squares method (PLS). The decision to use the PLS SEM method instead of another popular SEM technique relying on covariance matrices was driven by the two features of collected data: (1) most of the observable variables (indicators) did not have a multivariate normal distribution, which is a requirement for the covariance based SEM, and (2) the need to estimate formative constructs favors PLS SEM, which is recommended for such analysis tasks (Hair et al., 2014, p.15). In SmartPLS, $p$-values for statistical tests were obtained using bootstrapping with 5000 subsamples and the comparison of regression paths for different business models was accomplished with the multi-group analysis procedure.

\section{Research Findings}

Considering that the core part of the analysis involves contrasting structural models for three groups of firms, it is necessary to explore measurement invariance. According to Henseler et al. (2017, p. 409), measurement invariance ensures that different groupspecific regression weights do not result from distinctive content and the meanings of the reflective latent variables across groups. Our formative constructs have the same meanings because their scores were obtained by assuming the same contribution of each indicator across every group; with reflective constructs the meaning depends on factor loadings and these can vary across groups. If measurement invariance is missing, such differences are difficult to interpret. In this study, we investigated measurement invariance by comparing factor loadings for reflective constructs (Tab. 1) with a permutation test available in SMART PLS (Hair et al., 2017, pp. 159-161). The test results were all insignificant at the 0.05 level, pointing to a lack of meaningful differences between factor loadings. The sole exception was the statement "It is not possible for us to offer our products through other retail networks" ( $p=0.042$ ), but with four other measurement invariant statements under the same latent variable it is safe to assume that this will not be a source of substantive bias.
In contrast to the covariance-based SEM, in the partial least squares SEM there are no widely accepted overall goodness of fit tests, hence the model quality must be determined with individual metrics of internal consistency, convergent validity and discriminant validity (Hair et al., 2012). Factor loadings contained in Tab. 1 imply that all three structural equation models have acceptable quality because: Cronbach's alphas are greater than 0.6 (Malhotra, 2010, p. 287), AVEs (Average Variance Extracted) are higher than 0.5 (Hair et al., 2009), and for all reflective constructs AVEs are greater than MSVs (Maximum Shared Variance).

Once the quality of the underlying measurement model was deemed acceptable, standardized regression weights and $p$-values in Tab. 2 can be used for hypothesis testing. They inform about the strength and direction of relationships between latent variables in the structural model.

From Tab. 2, a total of 12 regression paths across all the three structural models have regression weights significantly different from zero. Regardless of the business model, the cooperative dimension of relationship was positively correlated with cooperation scope, and higher levels of cooperation scope corresponded with greater cooperation benefits. Also, the manufacturer's dependence on the key retailer had a positive link with cooperation benefits. This gives full support to hypotheses $\mathrm{H} 3 \mathrm{c}, \mathrm{H} 4 \mathrm{a}$ and $\mathrm{H} 4 \mathrm{c}$. $\mathrm{H} 1$ is true for Traditionalists and Market Players but not for Contractors, who did not show significant association between the manufacturer's dependence on the key retailer and the degree of cooperative aspects in the relationship with the retailer. Interestingly, Traditionalists had meaningful negative links between the manufacturer's dependence on the key retailer and the competitive dimension of the relationship, which is opposite to the direction hypothesized in $\mathrm{H} 2$.

To explore Hypothesis 5, multigroup comparisons were performed with the MGA tool in SmartPLS leading to the discovery of six significant differences between business models at the p-level of 0.05 . For Contractors, the manufacturer's dependence on the key retailer had a much weaker link with the degree of cooperative relations than for Market Players and Traditionalists. Market Players and Traditionalists were apparently unwilling to engage in close cooperation with 
the dominant partner, while for Contractors there was no such effect. With Market Players the correlation between the scope of cooperation and benefits was stronger than for either Contractors or Traditionalists. Finally, Traditionalists showed much stronger positive direct effects between the manufacturer's dependence on the key retailer and cooperation benefits in comparison to Market Players and Traditionalists. The existence of these differences in some but not all regression paths gives partial support to $\mathrm{H} 5$.

Overall, the whole structural model explained $28.7 \%$ of variance in relationship

\section{Tab. 2: Regression weights with significance tests for estimated path models}

\begin{tabular}{|c|c|c|c|c|c|c|c|}
\hline \multirow[b]{2}{*}{ 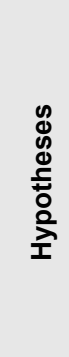 } & \multirow[b]{2}{*}{ Regression paths } & \multicolumn{2}{|c|}{$\begin{array}{l}\text { Traditionalists } \\
\quad \mathrm{n}=321\end{array}$} & \multicolumn{2}{|c|}{$\begin{array}{c}\text { Market Players } \\
n=128\end{array}$} & \multicolumn{2}{|c|}{$\begin{array}{c}\text { Contractors } \\
n=131\end{array}$} \\
\hline & & 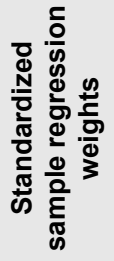 & 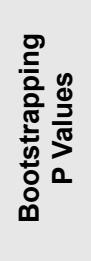 & 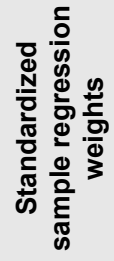 & 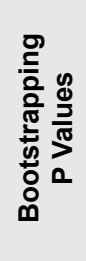 & 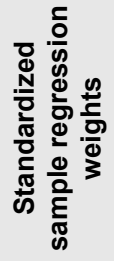 & 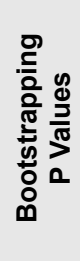 \\
\hline $\mathrm{H} 1$ & $\begin{array}{l}\text { Manufacturer's dependence } \\
\text { on the key retailer } \rightarrow \\
\text { Cooperative dimension of } \\
\text { the relationship }\end{array}$ & -0.418 & 0.000 & -0.463 & 0.000 & -0.007 & 0.971 \\
\hline $\mathrm{H} 2$ & $\begin{array}{l}\text { Manufacturer's dependence } \\
\text { on the key retailer } \rightarrow \\
\text { Competitive dimension of } \\
\text { the relationship }\end{array}$ & -0.219 & 0.024 & -0.199 & 0.360 & -0.200 & 0.176 \\
\hline $\mathrm{H} 3 \mathrm{a}$ & $\begin{array}{l}\text { Competitive dimension } \\
\text { of the relationship } \rightarrow \\
\text { Cooperation scope }\end{array}$ & 0.091 & 0.327 & 0.144 & 0.367 & 0.063 & 0.652 \\
\hline $\mathrm{H} 3 \mathrm{~b}$ & $\begin{array}{l}\text { Manufacturer's dependence } \\
\text { on the key retailer } \rightarrow \\
\text { Cooperation scope }\end{array}$ & 0.103 & 0.224 & 0.043 & 0.752 & 0.139 & 0.302 \\
\hline $\mathrm{H} 3 \mathrm{c}$ & $\begin{array}{l}\text { Cooperative dimension } \\
\text { of the relationship } \rightarrow \\
\text { Cooperation scope }\end{array}$ & 0.452 & 0.000 & 0.433 & 0.000 & 0.484 & 0.000 \\
\hline $\mathrm{H} 4 \mathrm{a}$ & $\begin{array}{l}\text { Cooperation scope } \rightarrow \\
\text { Cooperation benefits }\end{array}$ & 0.362 & 0.000 & 0.624 & 0.000 & 0.294 & 0.018 \\
\hline $\mathrm{H} 4 \mathrm{~b}$ & $\begin{array}{l}\text { Cooperative dimension } \\
\text { of the relationship } \rightarrow \\
\text { Cooperation benefits }\end{array}$ & 0.057 & 0.517 & 0.021 & 0.823 & -0.023 & 0.833 \\
\hline $\mathrm{H} 4 \mathrm{c}$ & $\begin{array}{l}\text { Manufacturer's dependence } \\
\text { on the key retailer } \rightarrow \\
\text { Cooperation benefits }\end{array}$ & 0.433 & 0.000 & 0.216 & 0.048 & 0.247 & 0.043 \\
\hline $\mathrm{H} 4 \mathrm{~d}$ & $\begin{array}{l}\text { Competitive dimension } \\
\text { of the relationship } \rightarrow \\
\text { Cooperation benefits }\end{array}$ & -0.002 & 0.987 & -0.234 & 0.278 & -0.089 & 0.387 \\
\hline
\end{tabular}


benefits for Traditionalists, $42.1 \%$ for Market Players and $16.8 \%$ for Contractors.

Considering total effects along both direct and indirect paths, the manufacturer's dependence on the key retailer explained $13.8 \%$ of variance in cooperation benefits reported by Traditionalists, while for Contractors and Market Players it was $9.1 \%$ and $1.8 \%$, respectively. For all business models, despite differences in effect sizes, greater manufacturer dependence on the key retailer seemed to induce more relationship benefits.

To verify the robustness of the hypothesis tests, we investigated possible moderation effects with the ownership status of the manufacturer (only Polish vs. various levels of foreign capital) and its size (medium or large firms according to the employment criterion with the split point at 250 employees).

The fractions of respective business models in each of the four subgroups are presented in Tab. 3.

Interestingly, all subgroups have very similar structures in terms of business models used, which is confirmed by insignificant outcomes of the chi-square tests of independence. This suggests that the choice of a business model was not driven by the size or the ownership status of a company, implying that the business model taxonomy employed in this research was appropriate.
Using the same tool for multigroup analysis in SMART PLS as previously for comparing business models, we obtained significance values for regression weight differentials computed for respective pairwise combinations of firms.

Splitting the sample into large and medium companies revealed five significant differences in regression weights across the three business models. Perhaps most interestingly, large Traditionalists had a positive link between their dependence on the key retailer and the extent of the competitive relationship (0.428), while the medium ones showed a negative association $(-0.310)$ with a difference between the two at 0.738. Furthermore, the more competitive was a large Traditionalist's relationship with the retailer, the more negative was its impact on cooperation benefits $(-0.458)$. In medium firms, such an effect was not found (0.022). These two observations seem to correspond with one of the defining traits of the traditionalist business model: a sense of independence, which is arguably stronger among large versus medium Traditionalist. This sentiment can lead to the development of antagonistic interactions if the balance of power is strongly in favor of a business partner, thus, posing a threat to the manufacturer's independence. However, it seems that such an attitude is harmful to large Traditionalists, as competitive relationships appear to diminish relationship benefits.

\begin{tabular}{|c|c|c|c|c|c|}
\hline Tab. 3: & \multicolumn{5}{|c|}{$\begin{array}{l}\text { Frequency distributions of business models in each employment } \\
\text { and ownership group }\end{array}$} \\
\hline \multirow{2}{*}{\multicolumn{2}{|c|}{ Business models }} & \multicolumn{2}{|c|}{ Employment } & \multicolumn{2}{|c|}{ Ownership } \\
\hline & & $\begin{array}{c}\text { Medium } \\
\text { (50-249 } \\
\text { employees) }\end{array}$ & $\begin{array}{c}\text { Large } \\
\text { (at least } 250 \\
\text { employees) }\end{array}$ & $\begin{array}{l}\text { Only Polish } \\
\text { capital }\end{array}$ & $\begin{array}{c}\text { Foreign } \\
\text { capital }\end{array}$ \\
\hline \multirow{2}{*}{ Traditionalist } & Count & 233 & 88 & 115 & 206 \\
\hline & $\%$ & $57.4 \%$ & $50.6 \%$ & $56.4 \%$ & $54.8 \%$ \\
\hline \multirow{2}{*}{ Market player } & Count & 83 & 45 & 49 & 79 \\
\hline & $\%$ & $20.4 \%$ & $25.9 \%$ & $24.0 \%$ & $21.0 \%$ \\
\hline \multirow{2}{*}{ Contractor } & Count & 90 & 41 & 40 & 91 \\
\hline & $\%$ & $22.2 \%$ & $23.6 \%$ & $19.6 \%$ & $24.2 \%$ \\
\hline \multirow{2}{*}{ Whole sample } & Count & 406 & 174 & 204 & 376 \\
\hline & $\%$ & $100.0 \%$ & $100.0 \%$ & $100.0 \%$ & $100.0 \%$ \\
\hline \multicolumn{2}{|c|}{$\begin{array}{l}\text { Chi-square tests } \\
\text { of independence }\end{array}$} & \multicolumn{2}{|c|}{$\begin{array}{l}\text { Pearson chi-square }=2.748 \\
d f=2 ; p \text {-value }=0.253\end{array}$} & \multicolumn{2}{|c|}{$\begin{array}{l}\text { Pearson chi-square }=1.839 \\
d f=2 ; p \text {-value }=0.399\end{array}$} \\
\hline
\end{tabular}




\begin{tabular}{|c|c|c|c|c|c|c|c|}
\hline Tab. 4: & \multicolumn{7}{|c|}{$\begin{array}{l}\text { Regression weight differentials with significance values for large } \\
\text { and medium-sized traditionalists, market players and contractors }\end{array}$} \\
\hline \multirow[b]{2}{*}{ 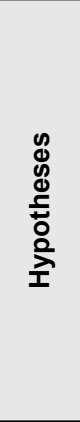 } & \multirow[b]{2}{*}{ Regression paths } & \multicolumn{2}{|c|}{$\begin{array}{l}\text { Traditionalists } \\
\qquad \mathrm{n}=321\end{array}$} & \multicolumn{2}{|c|}{$\begin{array}{l}\text { Market Players } \\
\quad n=128\end{array}$} & \multicolumn{2}{|c|}{$\begin{array}{c}\text { Contractors } \\
n=131\end{array}$} \\
\hline & & 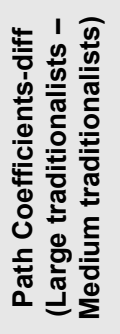 & 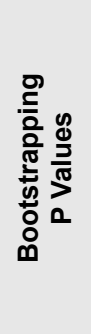 & 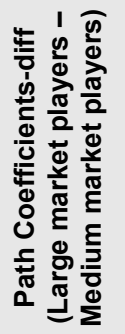 & 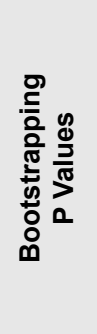 & 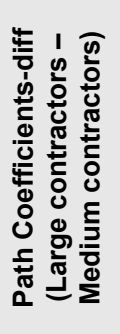 & 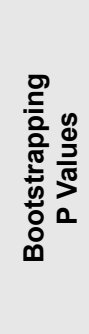 \\
\hline $\mathrm{H} 1$ & $\begin{array}{l}\text { Manufacturer's dependence } \\
\text { on the key retailer } \rightarrow \\
\text { Cooperative dimension of } \\
\text { the relationship }\end{array}$ & 0.230 & 0.492 & -0.026 & 0.900 & -0.322 & 0.410 \\
\hline $\mathrm{H} 2$ & $\begin{array}{l}\text { Manufacturer's dependence } \\
\text { on the key retailer } \rightarrow \\
\text { Competitive dimension of } \\
\text { the relationship }\end{array}$ & 0.738 & 0.038 & -0.245 & 0.499 & 0.194 & 0.600 \\
\hline $\mathrm{H} 3 \mathrm{a}$ & $\begin{array}{l}\text { Competitive dimension } \\
\text { of the relationship } \rightarrow \\
\text { Cooperation scope }\end{array}$ & 0.235 & 0.308 & -0.312 & 0.273 & -0.092 & 0.756 \\
\hline $\mathrm{H} 3 \mathrm{~b}$ & $\begin{array}{l}\text { Manufacturer's dependence } \\
\text { on the key retailer } \rightarrow \\
\text { Cooperation scope }\end{array}$ & 0.118 & 0.597 & 0.411 & 0.093 & -0.032 & 0.907 \\
\hline $\mathrm{H} 3 \mathrm{c}$ & $\begin{array}{l}\text { Cooperative dimension } \\
\text { of the relationship } \rightarrow \\
\text { Cooperation scope }\end{array}$ & -0.101 & 0.618 & 0.352 & 0.048 & 0.213 & 0.255 \\
\hline $\mathrm{H} 4 \mathrm{a}$ & $\begin{array}{l}\text { Cooperation scope } \rightarrow \\
\text { Cooperation benefits }\end{array}$ & 0.122 & 0.476 & -0.074 & 0.736 & 0.419 & 0.043 \\
\hline $\mathrm{H} 4 \mathrm{~b}$ & $\begin{array}{l}\text { Cooperative dimension } \\
\text { of the relationship } \rightarrow \\
\text { Cooperation benefits }\end{array}$ & 0.010 & 0.965 & 0.170 & 0.496 & 0.150 & 0.563 \\
\hline $\mathrm{H} 4 \mathrm{C}$ & $\begin{array}{l}\text { Manufacturer's dependence } \\
\text { on the key retailer } \rightarrow \\
\text { Cooperation benefits }\end{array}$ & -0.056 & 0.817 & -0.008 & 0.981 & 0.093 & 0.766 \\
\hline $\mathrm{H} 4 \mathrm{~d}$ & $\begin{array}{l}\text { Competitive dimension } \\
\text { of the relationship } \rightarrow \\
\text { Cooperation benefits }\end{array}$ & -0.509 & 0.076 & 0.208 & 0.534 & 0.114 & 0.660 \\
\hline
\end{tabular}

Source: own elaboration

Also, large Market Players tend to display stronger associations between cooperation scope and its two antecedents: the manufacturer's dependence on the key retailer and the competitive dimension of the relationship (differences in regression weights of 0.411 and 0.352 , respectively). As was explained earlier, part of Market Players' strategy is enhancing the scope of cooperation to benefit from synergies with business partners. This finding implies that larger Market Players might have more resources and possibilities to establish more comprehensive relationships.

Large Contactors have economies of scale and more experience, which seemingly brings more benefits from the same scope of 
cooperation than their smaller counterparts (a difference of 0.419). At the core of Contractors' business model is providing manufacturing services to retailers, making volume and unit cost crucial aspects of profitability, which is reflected in our research.

The above insights modify the testing outcomes of some hypotheses. $\mathrm{H} 2$ is supported for large Traditionalists, while it still shows the opposite-than-anticipated relationships for medium Traditionalists and Market Players of both sizes. Although $\mathrm{H} 3 \mathrm{~b}$ was rejected for the whole sample, accounting for the firm size provided evidence that it could be true for large Market Players. Finally, H4d can be deemed confirmed for large Traditionalists (but when firms of both sizes were pooled together, there were no significant relationships of any kind).

When the firms were split according to the dominant source of capital, the only meaningful difference (at the 10\% significance level) between Polish and foreign owned manufacturers was the regression path for Market Players from the competitive dimension of the relationship to the scope of cooperation. Polish owned Market Players had a regression weigh greater by 0.503 than their foreign counterparts, implying that there is a stronger positive link between competitive aspects of the relationship and the number of cooperation areas for Polish Market Players. Because no other significant effects were found, we chose not to include a table with detailed regression weight comparisons to save space. This outcome modifies the testing results of $\mathrm{H} 3 \mathrm{a}$, which seems to be supported in the subgroup of Market Players with solely Polish ownership. Other comparisons did not yield significant results suggesting similar causal mechanism in both groups of companies, which permits to keep in force the test results of pertinent hypotheses.

\section{Conclusions, Recommendations and Limitations of the Study \\ 4.1 Theoretical Implications of the Study}

The findings point to the coexistence of cooperation and competition between manufacturers and their key retailers, suggesting the coopetitive nature of this relations. This conclusion is borne out by a significant, positive correlation between the latent variables representing competitive and cooperative aspects of the relationship (Pearson's $\mathrm{R}=0.4$ for the whole sample). The correlation indicates that both aspects of the relationship change in the same direction in response to varying levels of the power of the key retailer.

The role of the manufacturer's dependence on the key retailer is only partially congruent with the authors' expectations. It seems that the manufacturer's dependence does not have a significant effect, either positive or negative, on competitive behavior in two subgroups of companies: Market Players and Contractors. A considerable negative association does exist for large Traditionalists, while medium Traditionalists show a weak negative correlation. At the same time, stronger dependence on the key retailer coincided with weaker cooperative behavior among Traditionalists and Market Players. Interestingly, Contractors did not show any meaningful links between dependence on the retailer and the competitive and collaborative nature of the relationship.

These findings imply that many manufacturers are unwilling to enter into a partnership with too strong retailers, due to a risk of an even greater dependence on the partner and a lock-up in a long-term, possibly inflexible arrangement that can turn unfavourable over time. This was the strongest for Traditionalists, who according to the characteristics of the business model are fiercely independent, sometimes even despite lacking adequate resources, and Market Players, who are aggressive and expansionistic, and would perceive higher dependence levels as a threat to their market position and strategy. Conversely, this pattern was not found in Contractors, possibly because this business model is built around dependence on retailers that are strong enough to be developing their own brands but outsourcing their production.

Literature suggests that rivalry and conflicts in inter-organizational relations rather than being triggered by adversarial actions of a partner, can be a function of the intensity of cooperation (Chow et al., 2011) and governance. Power balance in business relations was proposed to be an effective tool for achieving compatibility of goals, unifying organizational cultures and processes, reducing inter-organizational conflicts (Lacoste, 2016), and promoting the intensity of cooperation. In this study, we 
measured the imbalance of power in favor of the key retailer, who can use it to enforce more centralized governance schemes that, although hampering the intensity of cooperation, can result in more ordered and streamlined routines which contribute to lower ambiguity and thus opportunities for conflict. What could have lowered the reported competitiveness in manufacturer-retailer relations for Traditionalists was "explicitness of governance", expressed in precisely defined responsibilities and roles in manufacturing contracts (Brown et al., 2006).

The negative correlation between the manufacturer's dependence on the focal retailer and the competitive dimension of the relationship could be partially explained by the already mentioned positive links between cooperative and competitive elements of the relation (i.e. weaker cooperation leads to fewer occasions for conflict) and more ordered interactions. Also, manufacturers who are markedly weaker than their retailers might try to consciously avoid occasions for conflict out of fear of retribution by the retailer, for example through downsizing production orders. This is congruent with several previous studies where evidence was found for negative outcomes in supplier-retailer cooperation arising from conflicts between partners (Radaev, 2013). This is especially relevant for manufacturers employing multi-channel distribution strategies combining traditional and online channels (Kim \& Chun, 2018).

Despite anecdotal evidence to the contrary, high dependence of the manufacturer on its key retailer can in fact increase the amount of benefits for manufacturers. This effect was particularly pronounced for Traditionalists, probably due to the largest room for improvement that these types of companies could achieve through interactions with a more powerful and better organized retailing partner. Here, we can speculate, that the main source of benefits is the adoption of know-how (e.g. in marketing) and new skills, which can foster among other effects - enhanced productivity (e.g. due to cooperation with the retailer in launching new products, brand development and joint promotions). Also, a better utilization of production capacity could be of issue. This explanation ties in closely with the findings of a recent quantitative study on value cocreation by cooperating manufacturers and retailers (Chaurasia, 2018). The study reported that sharing technical, cultural and strategic resources builds competencies and leads to competitive advantages for retailers and manufacturers. We believe that similar effect occurred in our research. Close cooperation can even lead to fundamental changes in business models, which were found to be "continuously emergent and transient" (La Rocca \& Snehota, 2017); here, one likely transition is a Traditionalist transforming into a Contractor, under pressure from the key retailer if benefits are clear.

It seems that Contractors - in contrast to firms employing other business models - are so strongly dependent on orders from retailers that they do not hesitate to develop close cooperative ties even with much stronger partners. This pattern fits with their main defining attribute of producing goods under retailer brands, rather than their own brands. On the other hand, both Traditionalists and Market Players appear to be more selective and choose to cooperate with weaker rather than stronger retailing partners. Empirical research of Gómez and Rubio Benito (2008) supports the rationale for cooperation in manufacturing of private labels by "non-leading manufacturers" and provides evidence against this practice by "leading manufacturers". Moreover, according to Gomez-Arias and BelloAcebron (2008), a "high-quality manufacturer" produces a private brand only if a retailer positions it as premium and a "low-quality manufacturer" is willing to make private labels independently of its positioning. In the taxonomy of business models adopted for this research, it was Contractors who typically did not own brands and could be hardly considered "leading manufacturers", thus this apparent lack of selectiveness on the part of Contractors with whom to cooperate finds support in theoretical thinking by other authors.

The position of Market Players is unique in that their benefits from cooperation are explained the most by the scope of the relationship rather than other factors. One explanation is that Market Players are more flexible than other business models, have better know-how and skill sets, and can more readily adjust the range of joint projects to optimize the use of shared skills and resources. Market Players, by definition, can cooperate in various value chain activities, such as R\&D, product and assortment design, launching new products or brands, manufacturing, logistics, stock management, 
sales promotion, co-branding, joint promotions and category management. Because of this extensive set of capacities, Market Players can more freely regulate the magnitude of partners' involvement, to maximize the amount of benefits.

\subsection{Managerial Recommendations}

The key practical conclusion is the observation that retailer-supplier relationships dominated by the key retailer are frequently a source of benefits to the involved manufacturer. These benefits are driven by the retailer sharing its resources that include, among other things, its distribution system, logistical experience, strong financial position, marketing expertise and brand image. It seems that to make use of this benefits it is worth the risk to enter a longterm cooperation with powerful retailers. This especially applies to firms that could benefit the most from new know-how (Traditionalists) and new manufacturing orders (Contractors).

From a practical standpoint what also matters is the nature of this relationship. Our research suggests that even though coopetition is a fact in manufacturer-retailer interactions, as shown by concomitant variance of cooperative and competitive elements of the relationship, it is unlikely to have substantive impacts on the scope of cooperation and its benefits. At the same time, the cooperative aspect of the relationship is significantly linked with an increased range of joint activities (directly) and achieved benefits (indirectly, through the mediation of cooperation scope). These effects were valid for all three types of business models, pointing to a possible universality of the pattern. There is no clear evidence in our data that competition between manufacturers and retailers is harmful, however if mitigating competitiveness could bolster the cooperative aspect of a relationship, this might be a noteworthy recommendation to managers. The possibilities to reduce competitiveness with retailers are available to all business models. Market Players, who are strong brand suppliers and often market leaders, could, for example, develop with retailers joint marketing programs aimed at improving consumer experience. Traditionalists, frequently secondary brand manufacturers, could consider curtailing their portfolio of own brands with weaker market positions, in favor of manufacturing private retailer labels (Hogarth-Scott, 1999). This would push the Traditionalist's business model to transform into that of a Contractor, as described by La Rocca and Snehota (2017). Contractors, in turn, could work together with retailers on improving technical and marketing quality of their products and optimizing operational processes.

\subsection{Limitations and Further Research Directions}

One weakness of the study is its focus on a single, transition economy, which can show different patterns of supply-chain cooperation than developed countries. However, we believe that such comparative analysis should yield similar results, due to Poland's deep integration with the biggest economies of the EU. Moreover, most of our sample was involved in exporting activities, many firms were co-owned by foreign capital and their key retailers were multinational chains. As another limitation, using alternative taxonomies of business models could reveal different contrasts and similarities among companies. It should also be noted that this study depends on evidence from only one side of the partnership - manufacturers. But the balance of power between the producer and retailer is also determined by the retailer's dependence of the producer. So, information about the bargaining power of each engaged party is not complete and hence could bias the results. We investigated the scope of cooperation between manufacturers and their key retailers, but the scope of competition between partners was not considered, and it could improve the explanatory power of the structural models (e.g. rivalry between similar products sold under manufacturer and retailer brands, or competition in distribution). This overview of limitations suggests several directions for further research. Follow-up studies could try to replicate our findings in different industrial and national contexts. They could employ a revised conceptual framework, for example by accounting not only for manufacturers' business models but also those followed by key retailers. Especially interesting would be to investigate dyads of partners. However, simultaneously studying pairs of partners in a quantitative survey may be very challenging to implement due to logistical problems and high costs of such research.

Acknowledgement: The project was funded by the National Science Centre grant conferred based on the decision No. UMO 2013/11/B/ HS4/02123. 


\section{References}

Ailawadi, K. L., Bradlow, E. T., Draganska, M., Nijs, V., Rooderkerk, R. P., Sudhir, K., ... Zhang, J. (2010). Empirical models of manufacturer-retailer interaction: A review and agenda for future research. Marketing Letters, 21(3), 273-285. https://dx.doi.org/ 10.1007/ s11002-010-9107-0

Amato, L. H., \& Amato, C. H. (2009). Changing retail power and performance in distribution channels. International Journal of Retail \& Distribution Management, 37(12), 1057-1076. https://dx.doi.org/10.1108/09590550911005029

Benson-Rea, M., Hinttu, S., \& Kock, S. (2003). Relationships of Cooperation and Competition Between Competitors. Paper submitted to the 19th Annual IMP Conference, September 4-6. Switzerland: Lugano. Retrieved May 18, 2015, from http://www. impgroup.org/ uploads/papers/4294.pdf

Benson-Rea, M., Brodie, R. J., \& Sima, H. (2013). The plurality of co-existing business models: Investigating the complexity of value drivers. Industrial Marketing Management, 42(5), 717-729. https://dx.doi.org/10.1016/j. indmarman.2013.05.011

Brito, E. P. Z., \& Mariotto, G. (2013). Benefits of cooperation between buyers and providers: A study in the field of information and communications technology. Review of Business Management, 15(47), 241-261. https://dx.doi.org/10.7819/rbgn.v15i47.1354

Brown, J. R., Cobb, A. T., \& Lusch, R. F. (2006). The roles played by interorganizational contracts and justice in marketing channel relationships. Journal of Business Research, 59(2), 166-175. https://doi.org/10.1016/j. jbusres.2005.04.004

Burt, S. L., \& Sparks, L. (2003). Power and competition in the UK retail grocery market. British Journal of Management, 14(3), 237-254. https://dx.doi.org/10.1111/1467-8551.00377

Chaurasia, S. S. (2018). I can't but we can!: Impact of goal compatibility on value cocreation in retailer-manufacturer outsourcing relationship. Journal of Global Operations and Strategic Sourcing, 11(1), 123-144. https://doi. org/10.1108/JGOSS-04-2017-0010

Chimhundu, R. (2011). Private Label Marketing Performance: An Analysis of Historical Trends Using Theories of Cumulative Change and Punctuated Equilibrium. International Journal of Business and Management, 6(8), 58-65. https://dx.doi.org/ 10.5539/ijbm.v6n8p58
Chow, C. S. F., Kaynak, E., \& Yang, C. J. (2011). Channel power struggle between a manufacturer giant and a retailer giant in China: Who is the winner?. Competitiveness Review: An International Business Journal, 21(3), 306-321. https://dx.doi.org/10.1108/10595421111134877

Corsten, D., \& Felde, J. (2005). Exploring the performance effects of key-supplier collaboration. International Journal of Physical Distribution \& Logistics Management, 35(6), 445-461. https://dx.doi. org/10.1108/09600030510611666

Corsten, D., \& Kumar, N. (2005). Do suppliers benefit from collaborative relationships with large retailers? An empirical investigation of efficient consumer response adoption. Journal of Marketing, 69(3), 80-94. https://dx.doi.org/10.1509/jmkg.69.3.80.66360

Cox, A., Sanderson, J., \& Watson, W. (2000). Power Regimes: Mapping the DNA of Business and Supply Chain Relationships. Boston: Earlsgate Press.

Dapiran, G. P., \& Hogarth-Scott, S. (2003). Are cooperation and trust being confused with power? An analysis of food retailing in Australia and the UK. International Journal of Retailing \& Distribution Management, 31(5), 256-267. https://dx.doi.org/10.1108/09590550310472424

Dudzik, T., Gołębiowski, T., \& WitekHajduk, M. (2008). Modele biznesu - aspekty teoretyczne. In T. Gołębiowski, T. Dudzik, M. Lewandowska, M. Witek-Hajduk, Modele biznesu polskich przedsiębiorstw. Warszawa: SGH.

Dudzik, T. M., \& Witek-Hajduk, M. K. (2007). Typologia modeli biznesu. Gospodarka Materiałowa i Logistyka, 9, 18-23.

Essabbara, D., Zrikemb, M., \& Zolghadri, M. (2016). Power imbalance in collaboration relationships. International Journal of Supply and Operations Management, 2(4), 1021-1034. https://dx.doi.org/10.22034/2015.4.04

Geraudel, M., \& Salvetat, D. (2014). What are the antecedents of coopetition?: An explanation in terms of centrality and personality traits. European Business Review, 26(1), 23-42. https://dx.doi.org/10.1108/EBR09-2012-0051

Gnyawali, D. R., Madhavan, R., He, J., \& Bengtsson, M. (2016). The competitioncooperation paradox in inter-firm relationships: A conceptual framework. Industrial Marketing Management, 53,7-18.https://doi.org/10.1016/j. indmarman.2015.11.014 
Gómez, M., \& Rubio Benito, N. (2008). Manufacturer's characteristics that determine the choice of producing store brands. European Journal of Marketing, 42(1/2), 154-177. https://dx.doi.org/10.1108/03090560810840952

Gomez-Arias, J. T., \& Bello-Acebron, L. (2008). Why do leading brand manufacturers supply private labels? Journal of Business \& Industrial Marketing, 23(4), 273-278. https://dx.doi.org/10.1108/08858620810865852

Hair, J. F., Hult, G. T., Ringle, C. M., \& Sarsredt, M., (2014). A primer on partial least squares structural equation modeling (PLS-SEM). Thousand Oaks, CA: SAGE.

Hair, J. F., Sarstedt, M., Ringle, C. M., \& Mena, J. A. (2012). An assessment of the use of partial least squares structural equation modeling in marketing research. Journal of the Academy of Marketing Science, 40(3), 414-433. https://doi.org/10.1007/s11747-0110261-6

Hair, J. F., Black, W., Babin, B., \& Anderson, R. (2009). Multivariate Data Analysis (7th ed.). Upper Saddle River, NJ: Pearson Prentice Hall.

Hair, J. F., Sarstedt, M., Ringle, C. M., \& Gudergan, S. P. (2017). Advanced Issues in Partial Least Squares Structural Equation Modeling (PLS-SEM). Thousand Oaks, CA: SAGE.

Halstead, D., \& Ward, C. B. (1995). Assessing the Vulnerability of Private Label Brands. Journal of Product \& Brand Management, 4(3), 38-48. https://dx.doi. org/10.1108/10610429510097636

Hamilton, G., \& Petrovic, M. (2011). Retailers as market makers, In G. Hamilton, M. Petrovic, B. Senauer (Eds.), The Market Makers: How Retailers are Reshaping the Global Economy (pp. 31-49). Oxford: Oxford University Press.

Henseler, J., Ringle, C. M., \& Sarstedt, M. (2016). Testing measurement invariance of composites using partial least squares. International Marketing Review, 33(3), 405431. https://doi.org/10.1108/IMR-09-2014-0304

Hogarth-Scott, S. (1999). Retailer-supplier partnerships: hostages to fortune or the way forward for the millennium? British Food Journal, 101(9), 668-682. https://dx.doi. org/10.1108/00070709910288865

Kallio, J., Tinnilä, M., \& Tseng, A. (2006). An international comparison of operatordriven business models. Business Process Management Journal, 12(3), 281-298. https://dx.doi.org/10.1108/14637150610667962
Kim, J.-C., \& Chun, S.-H. (2018). Cannibalization and competition effects on a manufacturer's retail channel strategies: Implications on an omni-channel business model. Decision Support Systems, 109, 5-14. https://doi.org/10.1016/j.dss.2018.01.007

Kim, S., Kim, N., Pae, J. H., \& Yip, L. (2013). Cooperate 'and' compete: coopetition strategy in retailer-supplier relationships. Journal of Business \& Industrial Marketing, 28(4), 263-275. https://dx.doi.org/10.1108/08858621311313875

Kotzab, H., \& Teller, C. (2003). Valueadding partnerships and co-opetition models in the grocery industry. International Journal of Physical Distribution \& Logistics Management, 33(3), 268-281. https://dx.doi. org/ 10.1108/09600030310472005

Kumar, N., \& Steenkamp, J.-B. (2007). Private Label Strategy: How to Meet the Store Brand Challenge. Brighton, MA: Harvard Business School Press.

La Rocca, A., \& Snehota, I. (2017). Business models in business networks - how do they emerge? IMP Journal, 11(3), 398-416. https://dx.doi.org/10.1108/IMP-07-2017-0039

Lacoste, S. (2016). Sustainable value co-creation in business networks. Industrial Marketing Management, 52, 151-162. https://dx.doi.org/10.1016/j.indmarman.2015.05.018

Lavie, D. (2006). The CompetitiveAdvantage of Interconnected Firms: An Extension of the Resource-Based View. Academy of Management Review, 31(3), 638-658. https://dx.doi.org/10.5465/amr.2006.21318922

Lusch, R. F., \& Brown, J. R. (1996). Interdependency, contracting, and relational behavior in marketing channels. Journal of Marketing, 60(4), 19-38. https://dx.doi. org/10.2307/1251899

Malhotra, N. (2010). Marketing Research: An Applied Orientation (7th ed.). Upper Saddle River, NJ: Prentice Hall.

Matopoulos, A., Vlachopoulou, M., Manthou, V., \& Manos, B. (2007). A conceptual framework for supply chain collaboration: empirical evidence from the agri-food industry. Supply Chain Management: An International Journal, 12(3), 177-186. https://dx.doi. org/10.1108/13598540710742491

Medcof, J. W. (2001). Resource-based Strategy and Managerial Power in Networks of Internationally Dispersed Technology Units. Strategic Management Journal, 22(11), 999-1012. https://dx.doi.org/10.1002/smj.192 
Oubiña, J., Rubio, N., \& Jesús Yagüe, M. (2006). Strategic management of store brands: an analysis from the manufacturer's perspective. International Journal of Retail \& Distribution Management, 34(10), 742-760. https://dx.doi. org/ 10.1108/09590550610691338

Osterwalder,A., Pigneur, Y., \& Tucci, C. (2005). Clarifying business models: Origins, Present, and Future of the Concept. Communications of Association for Information System, 16, 1-25. https://doi.org/10.17705/1CAIS.01601

Palmatier, R. W., Dant, R. P., Grewal, D., \& Evans, K. R. (2006). Factors influencing the effectiveness of relationship marketing: a metaanalysis. Journal of Marketing, 70(4), 136-153. https://dx.doi.org/10.1509/jmkg.70.4.136

Park, H. (2004). US retailers' cooperation with manufacturer promotional support. Journal of Fashion Marketing and Management, 8(4), 412-424. https://dx.doi.org/ 10.1108/13612020410560009

Park, N. K., Mezias, J. M., \& Song, J. (2004). A Resource-based View of Strategic Alliances and Firm Value in the Electronic Marketplace. Journal of Management, 30(1), 7-27. https://dx.doi.org/10.1016/j.jm.2002.11.001

Radaev, V. (2013). Market power and relational conflicts in Russian retailing. Journal of Business \& Industrial Marketing, 28(3), 167-177. https://dx.doi.org/10.1108/08858621311302822

Ritala, P., Golnam, A., \& Wegmann, A. (2014). Coopetition-based business models: The case of Amazon.com. Industrial Marketing Management, 43(2), 236-249. https://dx.doi. org/10.1016/j.indmarman.2013.11.005

Rubio, N., \& Jesús Yagüe, M. (2008). Store brand management and channel dependence: A model from the manufacturer's perspective. Journal of Brand Management, 15(4), 272-290. https://dx.doi.org/10.1057/palgrave. bm. 2550118

Soberman, D. A., \& Parker, P. M. (2006). The economics of quality-equivalent store brands. International Journal of Research in Marketing, 23, 125-39. https://dx.doi. org/10.1016/j.ijresmar.2005.09.008

Storbacka, K. (2011). A solution business model: Capabilities and management practices. Industrial Marketing Management, 40(5), 699-711. https://dx.doi.org/ 10.1016/j. indmarman.2011.05.003
Swoboda, B., Pop, N. A., \& Dabija, D. C. (2010). Vertical Alliances between Retail and Manufacturer Companies in the Fashion Industry. Amfiteatru Economic, 12(28), 634-649.

Tangpong, C., Michalisin, M. D., Traub, R. D., \& Melcher, A. J. (2015). A review of buyersupplier relationship typologies: progress, problems, and future directions. Journal of Business \& Industrial Marketing, 30(2), 153-170. https://dx.doi.org/10.1108/JBIM-102012-0193

Tellefsen, T., \& Thomas, G. P. (2005). The antecedents and consequences of organizational and personal commitment in business service relationships. Industrial Marketing Management, 34(1), 23-37. https:// doi.org/10.1016/j.indmarman.2004.07.001

Teller, C., Kotzab, H., Grant, D. B., \& Holweg, C. (2016). The importance of key supplier relationship management in supply chains. International Journal of Retail \& Distribution Management, 44(2), 109-123. https://dx.doi. org/10.1108/IJRDM-05-2015-0072

Trkman, P., Budler, M., \& Groznik, A. (2015). A business model approach to supply chain management. Supply Chain Management: An International Journal, 20(6), 587-602. https://dx.doi.org/10.1108/SCM-06-2015-0219

Vlachos, I. P., Bourlakis, M., \& Karalis, V. (2008). Manufacturer-retailer collaboration in the supply chain: empirical evidence from the Greek food sector. International Journal of Logistics Research and Applications, 11(4), 267-277. https://dx.doi.org/10.1080/13675560701768517

Witek-Hajduk, M. K. (2017). Manufacturer - retailer relationships. In M. K. Witek-Hajduk, J. Cygler, A. Sznajder, A. Napiórkowska \& T. Napiórkowski (Eds.), Manufacturer - retailer relationships. The context of business models. Warsaw: SGH.

Witek-Hajduk, M. K., \& Zaborek, P. (2016). Does Business Model Affect CSR Involvement? A Survey of Polish Manufacturing and Service Companies. Sustainability, 8(2), 93. https://dx.doi.org/10.3390/su8020093

Zott, C., Amit, R., \& Massa, L. (2011). The business model: recent developments and future research. Journal of Management, 37(4), 1019-1042. https://doi. org/10.1177/0149206311406265 